\title{
Prevalence of Mosquitoes in Gidan Yunfa Community of Usmanu Danfodiyo University, Sokoto, Nigeria
}

\section{Yahaya Muhammad Abdullahi ${ }^{1}$, Sani Abdullahi Fana ${ }^{1}$, Yusuf Salimat Umar ${ }^{1}$, Usman Salisu Batagarawa ${ }^{1}$,}

${ }^{1}$ Usmanu Danfodiyo University

P. M. B. 2346, Sokoto, Nigeria

DOI: $10.22178 /$ pos. $58-10$

LCC Subject Category: QH501-531

Received 23.04.2020

Accepted 28.05.2020

Published online 31.05.2020

Corresponding Author:

Yahaya Muhammad Abdullahi

abdullahi.yahaya@udusok.edu.ng

Abstract. Different species of mosquito serves as a vector for transmitting malaria. Malaria is still a serious public health problem in Nigeria. Knowledge of the mosquito species, their diversity, and their composition would help immensely toward proper implementation of the different control strategies. This study was carried out to determine the prevalence of mosquitoes and feeding or biting period in Gidan Yunfa community of Usmanu Danfodiyo University, Sokoto, Nigeria. The Larvae and Pupae were collected from breeding sites. Adult mosquitoes were sampled using CDC light traps (situated indoor and outdoor) and Pyrethrum Spray Catch methods. Mosquitoes were identified morphologically. A total of 6,410 adult mosquitoes with 2,142 (33.42\%) obtained from CDC light traps and 4,268 (66.58\%) from the larval collections were identified belonging to 3 genera Aedes, Anopheles, and Culex. A maximum number of mosquitoes were caught with CDC traps. The abundance of the different genera varied significantly $(P<0.05)$ with Anopheles having the highest occurrence $(54.75 \%)$ followed by Culex mosquitoes with $40.42 \%$. Aedes has the least abundance with $8.05 \%$. The indoor and outdoor feeding habits of the different species varied significantly $(P<0.05)$. Nature of the houses and tethering of animal in residential houses and abundance of breeding places may explain the reason behind the higher prevalence of the mosquito in this community.

Keywords: Aedes; Culex; Anopheles; CDC light trap; Gidan Yunfa.

\section{INTRODUCTION}

Mosquitoes as vectors are responsible for the transmission of many diseases. The report shows that many diseases such as malaria, dengue, yellow fever, etc. are transmitted to millions of people annually through mosquito vectors [17]. Approximately 3500 species of mosquitoes were reported from different parts of the world [1]. Several species serve as vectors for many infectious diseases [15] because of their abundance, vector capability, recurrent infection, and diversity [16]. In 2015 around the globe 50 to 200 million dengue incidences occurred with approximately 20,000 deaths [13]. It was shown that 36 mosquito-borne arboviruses were indigenous to Africa and regarded Africa as the source of most of the major mosquito-borne viruses of medical importance that currently constitute serious global public health threats [3].
Each of the four species of human malaria parasites is transmitted exclusively by Anopheles spp. [15]. Also, mosquitoes transmit filarial worms such as Wuchereria Bancroft and over 200 arboviruses to humans and other animals [15]. All age groups experience malaria, but the highest mortality occurs in children under the age of five years and pregnant women [19] purportedly due to their lower level of immunity [22]. More than $90 \%$ of deaths caused by malaria occur in Sub-Sahara an Africa and the disease is responsible for $50 \%$ of outpatient cases and $20 \%$ of hospital admissions [2]. In 2017, an estimated 219 million cases of malaria occurred worldwide with an estimated 435,000 deaths globally and most of these cases were in the WHO African Region (200 million or 92\%), with Nigeria accounting for $25 \%$ and is one of the 3 
countries with highest burden [23] which translate into an increase in malaria incidence in Nigeria in 2017 [23]. According to the World Malaria Report [23] children aged under 5 years account for $61 \%(226,000)$ of all malaria deaths worldwide in 2017.

Mosquitoes breed in different water bodies including manmade such as discarded tires, water tanks, bottles, cups, footprints of animals, etc [20, 6]. Factors including water temperature, vegetation, water currents, water sources, water quality affect mosquito distribution [20]. The presence of vast agricultural lands, open networks of irrigation channels, and rivers provide natural breeding sites for these vectors [10]. This study was aimed to find determine the mosquito species diversity, composition, feeding habit, and time within the study area.

\section{MATERIALS AND METHODS}

Study Area. The study was conducted from May to August 2019 in Gidan Yunfa community located within Usmanu Danfodiyo University, Sokoto (Latitude $13.1274{ }^{\circ} \mathrm{N}$, and Longitude $\left.5.2046^{\circ} \mathrm{E}\right)$. The people of the community are mostly farmers and a few fishermen.

Mosquito sample collection. Mosquito larvae were collected by the dipping method. A standard mosquito larval dipper ( $350 \mathrm{ml}$ each) with an extendable handle was used to collect larval specimens. Ten scoops were taken from each breeding site. Collected larvae in transparent plastic containers were transported to the Entomology Laboratory of Usmanu Danfodiyo University for rearing. Larvae were reared in plastic jars covered with a net of small mesh. Larvae were feed upon a mixture of yeast and biscuit.

Adult mosquitoes were captured both indoor and outdoor by using the CDC miniature light trap (Model 512, John W. Hock Co, Gainesville, Florida USA). This was done to determine the preference of the vector to feed indoors or outdoors and the peak time for biting. Each trap was operated from 1800 hours to 600 hours of the following morning. The collected mosquitoes were aspirated and placed in labeled paper cups and transported to the Entomology Laboratory of Usmanu Danfodiyo University for identification.

Identification of mosquito species. Adult mosquitoes were to a generic level. Identification was done morphologically using taxonomic keys $[8,7$, $12,5]$.

Data Analysis. The results so obtained were analyzed using the Chi-Square Test (X2) which was used to determine the level of significance at $\mathrm{P}<0.05$.

\section{RESULTS AND DISCUSSION}

Mosquito abundance. A total of 6,410 adult mosquitoes were collected from both CDC and emergence from the larval collection. Out of this number 2,142 (33.42\%) were obtained from CDC light traps and 4,268 (66.58\%) from the larval collections. The mosquitoes were morphologically identified belonging to 3 genera Aedes, Anopheles, and Culex.

CDC Monthly Collection. The total number of adult mosquito collected monthly from May to August is shown in Table 1.

Table 1 - Total monthly mosquito collection using CDC light traps

\begin{tabular}{|l|c|c|c|c|}
\hline Month & Indoor (\%) & $\begin{array}{c}\text { Outdoor } \\
(\%)\end{array}$ & Total (\%) & $\%$ \\
\hline May & $116(5.42)$ & $80(3.73)$ & $196(9.15)$ & 9 \\
\hline June & $34(1.59)$ & $18(0.84)$ & $52(2.43)$ & 2 \\
\hline July & $394(18.39)$ & $284(13.26)$ & $678(31.65)$ & 32 \\
\hline August & $662(30.91)$ & $554(25.86)$ & $\begin{array}{c}1216 \\
(56.77)\end{array}$ & 57 \\
\hline Total & $\begin{array}{c}1206 \\
(56.30)\end{array}$ & $936(43.70)$ & $2,142(100)$ & 100 \\
\hline
\end{tabular}

From the table, it's clear that a total of 2,142 which equals $33.42 \%$ prevalence were collected from both indoor and outdoor CDC light traps. Out of the 2,142 from CDC collection indoor yielded 1,206 (56.30\%) while outdoor gave 936 or $43.69 \%$ mosquitoes. The month of August had the highest abundance of adult mosquitoes with 1,216 mosquitoes which equals $56.77 \%$. This is followed by a July collection with a total of 678 which gave $32 \%$. Collection during May yielded 196 mosquitoes (9\%) and while June had the least is June with $2 \%$ (52) respectively. The Chisquare analysis shows a significant difference between indoor and outdoor collection ( $\mathrm{P}>0.05)$.

It is clear from Table 2 that out of the 2,142 obtained from CDC Anopheles has the highest prevalence with a total of 1,132 species representing $52.84 \%$. 
Table 2 - Total number and species of mosquito species obtained from CDC

\begin{tabular}{|l|c|c|c|c|c|}
\hline Gender & Anopheles (\%) & Culex (\%) & Aedes (\%) & Total & Prevalence, $\%$ \\
\hline Female & $984(45.94)$ & $568(26.52)$ & $52(2.43)$ & $1604(74.88)$ & 74.88 \\
\hline Male & $148(6.91)$ & $366(17.09)$ & $24(1.12)$ & $538(25.12)$ & 25.12 \\
\hline Total & $1,132(52.85)$ & $934(43.60)$ & $76(3.55)$ & $2142(100)$ & 100 \\
\hline
\end{tabular}

This is followed by the genus Culex with 934 species which equals $43.60 \%$. The genus Aedes had the least number of species with 76 representing $3.55 \%$ of the total collection. More females were captured than male mosquitoes. The Chi-Square analysis revealed a significant difference between the 3 genera and gender $(\mathrm{P}>0.05)$.

Mosquito obtained from larval collection. Figure 1 shows the number and species of mosquito obtained from larval sampling. The figure revealed that a total of 4,268 mosquitoes were obtained from larval collection. Species of the genus Anopheles has the highest abundance of $52.15 \%$ $(\mathrm{n}=2,226)$. Culex species closely followed with a prevalence of $30.37 \%(n=1,296)$. Aedes has the least number of occurrences of with $17.48 \%$ $(n=746)$.

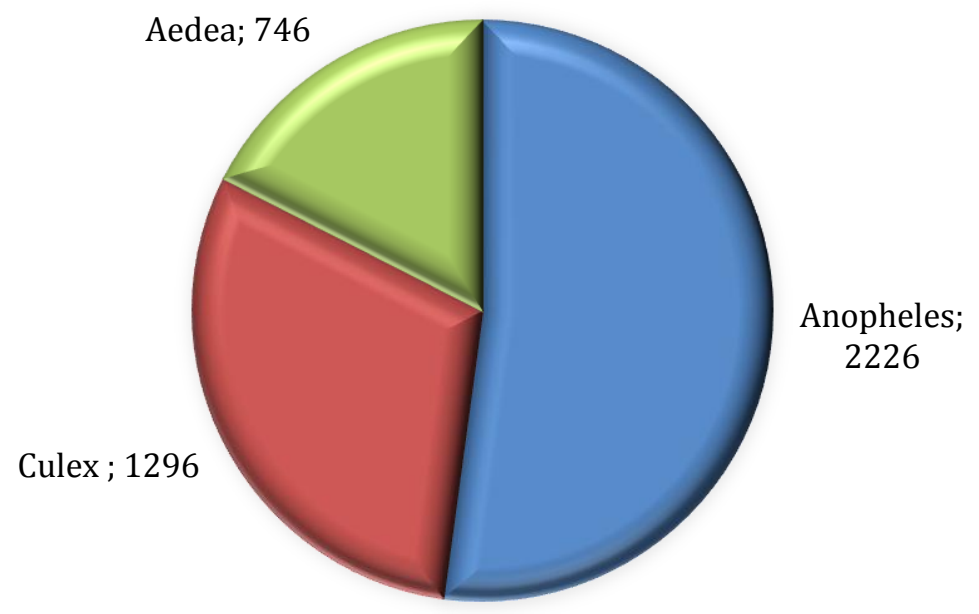

Figure 1 - Number of Mosquitoes obtained from the larval collection

Biting Time and Location. Figure 2 shows the hourly indoor biting time. It clear that the biting rates vary among the 3 genera of mosquito. The activity fluctuates on an hourly basis, particularly with Anopheles and Culex. There was an increase in biting activity 100-200 hrs with peak biting occurring between 300-400 hrs with Anopheles and Culex. There wasn't much feeding activity to Aedes indicating a significant difference in terms of feeding time and location.

A similar result was obtained outdoor to Anopheles and Culex (Figure 3). The biting period reaches a peak between 700-800 hrs. This goes down and shows some fluctuation in feeding with an increase in biting rate between 200-300 hrs case of Culex between 500-600 hrs. Less activity was observed in the case of Aedes with the peak reached 0900-1000 hrs. This slows down and remains static but raised again between 300-400 hrs. $\mathrm{X}^{2}$ analysis indicated a significant difference in feeding behavior between the genera $(\mathrm{P}>0.05)$.

The higher prevalence of Anopheles mosquito recorded from CDC and larval collection is an indication of the predominant status of the species within the study area. This finding is in agreement [4] who reported the predominant nature of Anopheles species in Katsina metropolis NorthWestern Nigeria. However, [18] reported a higher number of Culex in Ibadan southwestern Nigeria. The higher number of mosquitoes obtained in August could be attributed to the amount of rainfall which means more breeding sites and thus mosquito availability. It was re- 
ported [4] that rainy season favored breeding of mosquitoes than dry season therefore its availability. Within these periods the site normally experienced higher rainfall which translates to increase oviposition sites and the eventually higher number of mosquito vector which brought about the seasonal fluctuation in mosquito populations. These periods coincide with higher malaria transmission in the area.

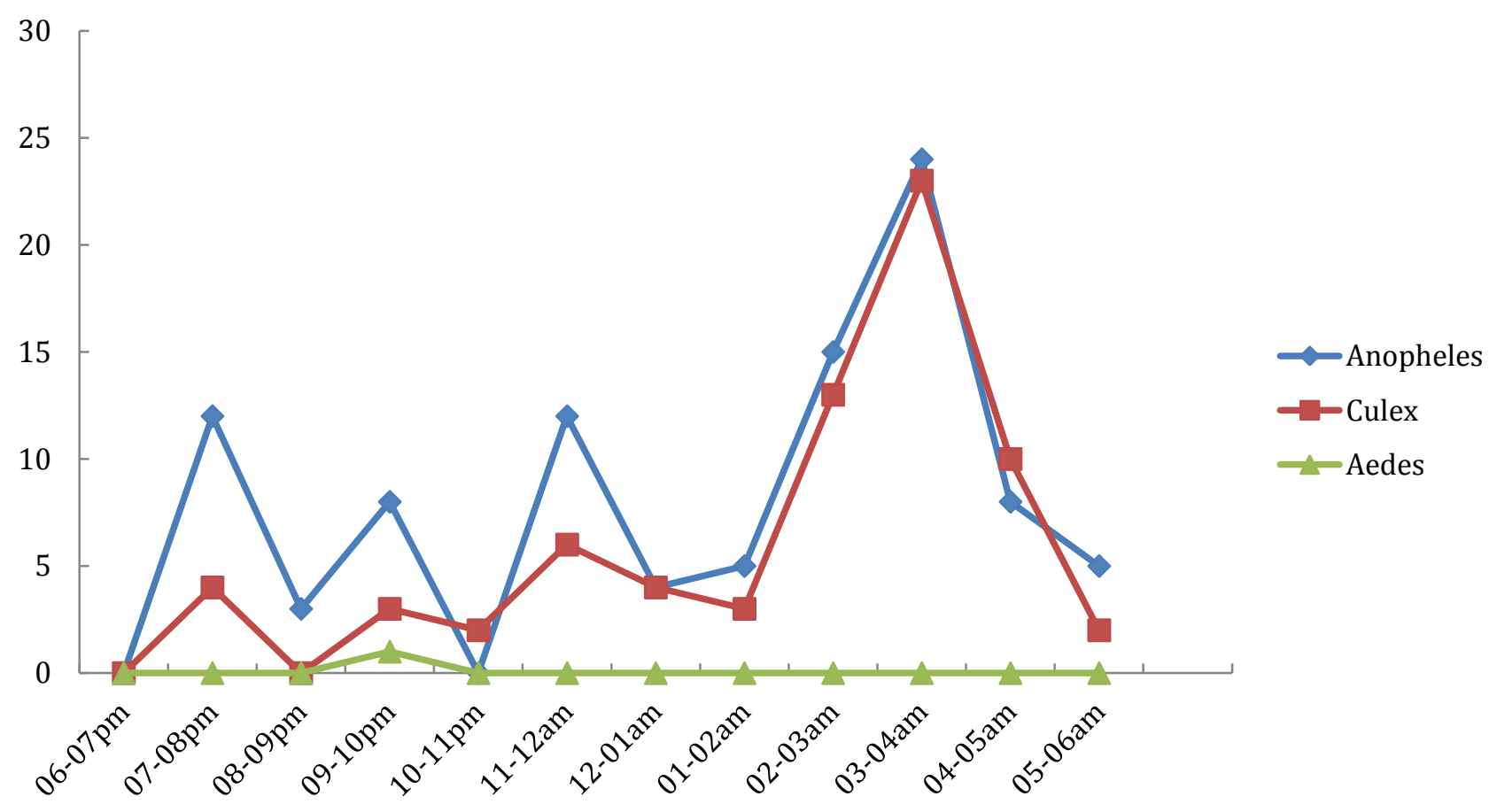

Figure 2 - Indoor hourly collection time of Anopheles, Culex and Aedes

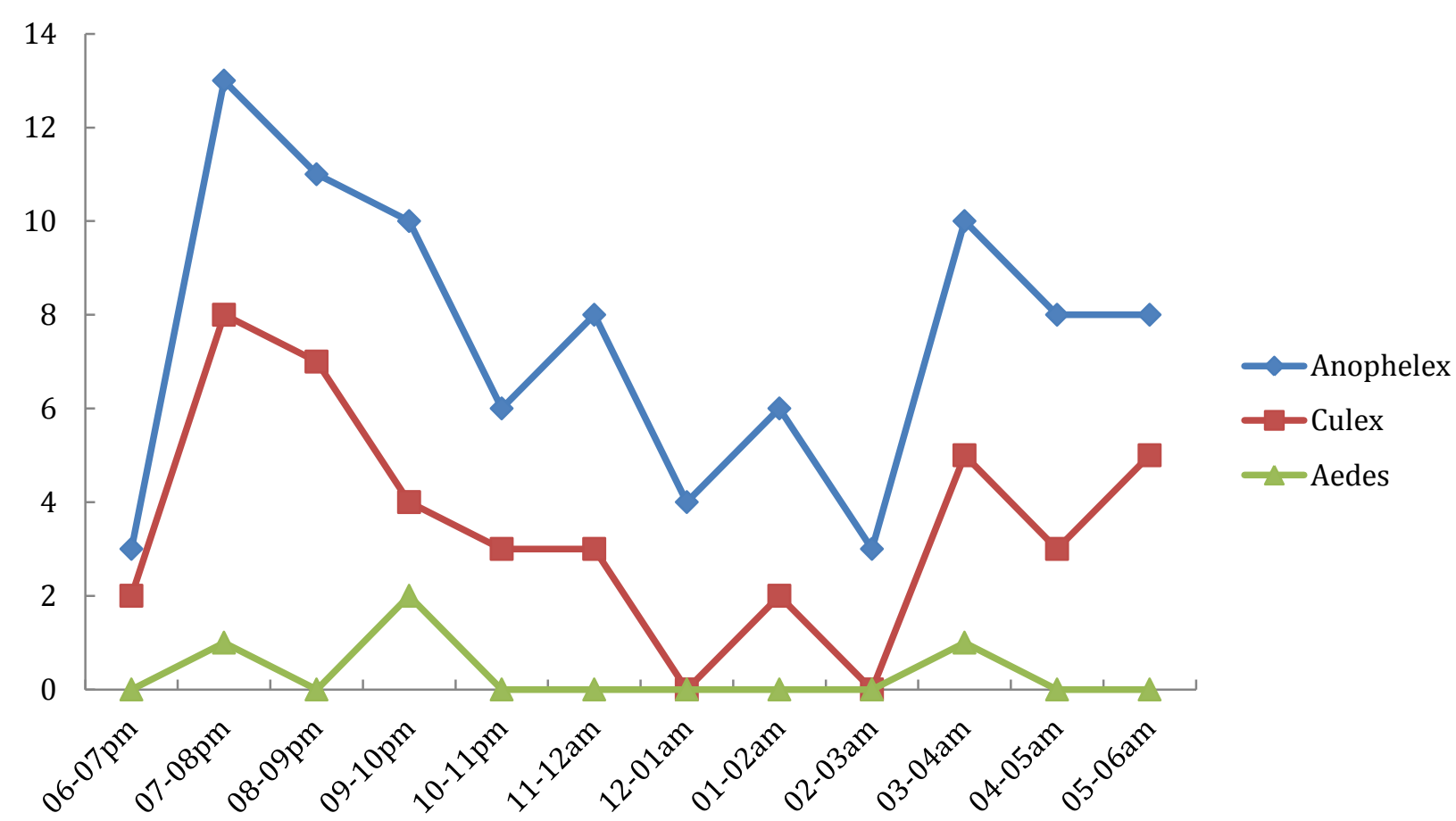

Figure 3 - Outdoor hourly collection time of Anopheles, Culex and Aedes

Indoor collection rates exceeded outdoor collection. Both indoor and outdoor captures were in- dicative of variation in the feeding habits of the different species of mosquitoes in the area. The 
higher indoor collection could be as a result of the fact that the inhabitants stay mostly indoors due to heavy downpour. Also Anopheles gambiae, the major malaria vector that has been suggested to be highly anthropophilic [14] and does have a strong preference for humans even when given other choices of blood hosts under controlled field settings. The higher number Anopheles and Culex captured by CDC traps buttressed the report that CDC light traps catch more anopheline and culicine mosquitoes [24]. The finding also agreed with the report [21] that CDC traps collected significantly more females of most species of mosquito. The less number of Aedes collected shows the difficulty of capturing diurnally active mosquitoes with commonly used adult traps such as the CDC light traps [9]. Also [11] added that CDC light traps are an efficient and productive means of collecting mosquitoes, both in consideration of the numbers of individuals captured and the diversity of species represented.

The variation in the abundance of the mosquitoes can be attributed to the difference in their breeding requirements and feeding habits. Anopheles mosquitoes breed in transient habitats such as shallow sunlit freshwater pools or human-made habitats, hoof prints, and tire tracks. Culex and Aedes are known to breed in polluted water bodies including open drains, open or cracked septic tanks, flooded pit latrines [18]. It was reported [15] that each species usually has a characteristic peak biting time or times, so Anopheles gambiae bites in the early hours of the morning, and Aedes aegypti shows two biting peaks, one at dawn and another at dusk. The findings of this study are in agreement with this assertion. Also while Anopheles and Culex mosquitoes are active during night time, dawn, and dusk, some mosquito species in the genus Aedes were observed actively biting humans during the day. This further confirmed the generalization that most anopheline species are night biters while the culicine contains both nights- and day-biting species [15].

\section{CONCLUSIONS}

Conclusively, the presence and diversity of these mosquito species constitute a major potential health problem for the inhabitants of the study area. And the indiscriminate use of agricultural chemicals may lead to the development of resistance and hamper efforts devised in control of these species. Consequently, understanding the biology and diversity of mosquito vectors is an essential tool in designing effective control strategies against these vectors.

\section{REFERENCES}

1. Aina, S. A., Banjo, A. D., Lawal, O. A., \& Jonathan, K. (2009). Efficacy of some plant extracts on Anopheles gambiae Mosquito Larvae. Academic Journal of Entomology, 2(1), 31-35.

2. Boutin, J. P., Pradines, B., Pagès, F., Legros, F., Rogier, C., \& Migliani, R. (2005). Epidémiologie du paludisme [Epidemiology of malaria]. La Revue du praticien, 55(8), 833-840.

3. Braack, L., Gouveia de Almeida, A. P., Cornel, A. J., Swanepoel, R., \& de Jager, C. (2018). Mosquitoborne arboviruses of African origin: review of key viruses and vectors. Parasites \& Vectors, 11(1). doi: 10.1186/s13071-017-2559-9

4. Bunza, M., Suleiman, A., Yusuf, A., \& Bala, A. (2011). Relative abundance of mosquito species in Katsina Metropolis, Katsina State, Nigeria. Nigerian Journal of Parasitology, 31(2). doi: 10.4314/njpar.v31i2.69470

5. Coetzee, M. (2020). Key to the females of Afrotropical Anopheles mosquitoes (Diptera: Culicidae). Malaria Journal, 19(1). doi: 10.1186/s12936-020-3144-9

6. Dom, N. C., Ahmad, A. H., \& Ismail, R. (2013). Habitat Characterization of Aedes Sp. Breeding in Urban Hotspot Area. Procedia - Social and Behavioral Sciences, 85, 100-109. doi: 10.1016/j.sbspro.2013.08.342

7. Gillies, M. T., \& Coetzee, M. (1987). A Supplement to the Anophelinae of Africa South of the Sahara. Publications of the South African Institute for Medical Research, 13(54).

8. Gillies, M. T., \& De Meillon, B. (1968). The Anophelinae of Africa South of the Sahara (Ethiopian Zoogeographical Region). Publications of the South African Institute for Medical Research, 54. 
9. Hassan, M., Al Ashry, H., Shobrak, M., \& Kenawy, M. (2016). Seasonal Abundance of the Common Mosquitoes: Culex pipiens, Cx. quinquefasciatus and Cx. sitiens (Diptera: Culicidae) in the Western Coast of Saudi Arabia. Egyptian Academic Journal of Biological Sciences, E. Medical Entomology \& Parasitology, 8(1), 13-22. doi: 10.21608/eajbse.2016.14485

10. Ilahi, I., \& Suleman, M. (2013). Species composition and relative abundance of mosquitoes in Swat, Pakistan. International Journal of Innovation and Applied Studies, 2(4), 454-463.

11. Kenawy, M., Ashry, H., Hassan, M., \& Shobrak, M. (2018). Efficiency of three light traps for sampling Mosquitoes in the Western regions of Saudi Arabia. International Journal of Mosquito Research, 5(1), 138-142

12. Kent, R. J. (2006, March). The Mosquitoes of Macha, Zambia (Doctoral thesis), Johns Hopkins Malaria Research Institute. Retrieved from https://static1.squarespace.com/static/58d002f017bffcf99fe21889/t/5a7ca49dc830259e7ce0 6a3f/1518118071358/TheMosquitoesofMachaZambia031506_000.pdf

13. Khan, J., \& Khan, A. (2015). Incidence of dengue in 2013: Dengue outbreak in District Swat, Khyber Pakhtunkhwa, Pakistan. International Journal of Fauna and Biological Studies, 2(1), 50-56.

14. Killeen, G. F., McKenzie, F. E., Foy, B. D., Bøgh, C., \& Beier, J. C. (2001). The availability of potential hosts as a determinant of feeding behaviours and malaria transmission by African mosquito populations. Transactions of the Royal Society of Tropical Medicine and Hygiene, 95(5), 469-476. doi: 10.1016/s0035-9203(01)90005-7

15. Lehane, M. J. (2005). The Biology of Blood-Sucking in Insects. Cambridge: Cambridge University Press.

16. Njabo, K. Y., Smith, T. B., Yohannes, E. (2013). Feeding habits of culicine mosquitoes in the Cameroon lowland forests based on stable isotopes and blood meal analyses. Journal of Parasitology and Vector Biology, 5(1), 6-12.

17. Noutcha, M. A., \& Anumdu, C. I. (2009). Entomological indices of Anopheles gambiae sensu lato at a rural community in south-west Nigeria. Journal of vector borne diseases, 46(1), 43-51.

18. Okorie, P. N., Popoola, K. O., Awobifa, O. M., Ibrahim, K. T., \& Ademowo, G. O. (2014). Species composition and temporal distribution of mosquito populations in Ibadan, Southwestern Nigeria. Journal of entomology and zoology studies, 2(4), 164-169.

19. Phillips, R. S. (2001). Current Status of Malaria and Potential for Control. Clinical Microbiology Reviews, 14(1), 208-226. doi: 10.1128/cmr.14.1.208-226.2001

20. Rattanarithikul, R., Harrison, B. A., Panthusiri, P., \& Coleman, R. E. (2005). Illustrated keys to the mosquitoes of Thailand I. Background; geographic distribution; lists of genera, subgenera, and species; and a key to the genera. The Southeast Asian journal of tropical medicine and public health, 36 Suppl 1, 1-80.

21. Reisen, W. K., Boyce, K., Cummings, R. C., Delgado, O., Gutierrez, A., Meyer, R. P., \& Scott, T. W. (1999). Comparative effectiveness of three adult mosquito sampling methods in habitats representative of four different biomes of California. Journal of the American Mosquito Control Association, 15(1), 24-31.

22. World Health Organization. (2006). Africa Malaria Report. Geneva: WHO.

23. World Health Organization. (2018). World Malaria Report. Geneva: WHO.

24. Zaim, M., Ershadi, M. R., Manouchehri, A. V., \& Hamdi, M. R. (1986). The use of CDC light traps and other procedures for sampling malaria vectors in southern Iran. Journal of the American Mosquito Control Association, 2(4), 511-515. 